\title{
GANT61 and Lithium Chloride Inhibit the Growth of Head and Neck Cancer Cell Lines Through the Regulation of GLI3 Processing by GSK3 $\beta$
}

\author{
Vedran Zubčić ${ }^{1,2, \dagger}$, Nikolina Rinčić ${ }^{3, \dagger}$, Matea Kurtović ${ }^{3}$, Diana Trnski ${ }^{3}$, Vesna Musani ${ }^{3} \mathbb{D}$, \\ Petar Ozretić $^{3}$ (D) , Sonja Levanat ${ }^{3}$, Dinko Leović ${ }^{2,4, *}$ and Maja Sabol ${ }^{3, *(\mathbb{D})}$ \\ 1 Department of Maxillofacial Surgery, University Hospital Osijek, Ulica Josipa Huttlera 4, Osijek 31000, \\ Croatia; takeshi.zubcic@gmail.com \\ 2 School of Medicine, The Josip Juraj Strossmayer University of Osijek, Trg Svetog Trojstva 3, \\ Osijek 31000, Croatia \\ 3 Laboratory for Hereditary Cancer, Division of Molecular Medicine, Ruđer Bošković Institute, \\ Bijenička cesta 54, Zagreb 10000, Croatia; nikolina.rincic@irb.hr (N.R.); matea.kurtovic@irb.hr (M.K.); \\ diana.trnski@irb.hr (D.T.); vmusani@irb.hr (V.M.); pozretic@irb.hr (P.O.); levanat@irb.hr (S.L.) \\ 4 Department of Otorhinolaryngology and Head and Neck Surgery, Maxillofacial Surgery Unit, \\ Clinical Hospital Centre Zagreb, Kišpatićeva ulica 12, Zagreb 10000, Croatia \\ * Correspondence: dinko.leovic@gmail.com (D.L.); maja.sabol@irb.hr (M.S.); Tel.: +385-1-2388-888 (D.L.); \\ +385-1-4560-997 (M.S.) \\ + These authors contributed equally to this work.
}

Received: 11 August 2020; Accepted: 1 September 2020; Published: 3 September 2020

\begin{abstract}
Several signaling pathways are aberrantly activated in head and neck squamous cell carcinoma (HNSCC), including the Hedgehog-Gli (HH-GLI), WNT, EGFR, and NOTCH pathways. The HH-GLI pathway has mostly been investigated in the context of canonical signal transduction and the inhibition of the membrane components of the pathway. In this work we investigated the role of downstream inhibitors GANT61 and lithium chloride ( $\mathrm{LiCl}$ ) on cell viability, wound closure, and colony forming ability of HNSCC cell lines. Five HNSCC cell lines were treated with HH-GLI pathway inhibitors affecting different levels of signal transduction. GANT61 and LiCl reduce the proliferation and colony formation capabilities of HNSCC cell lines, and $\mathrm{LiCl}$ has an additional effect on wound closure. The major effector of the HH-GLI signaling pathway in HNSCC is the GLI3 protein, which is expressed in its full-length form and is functionally regulated by GSK3 $\beta$. LiCl treatment increases the inhibitory Ser9 phosphorylation of the GSK3 $\beta$ protein, leading to increased processing of GLI3 from full-length to repressor form, thus inhibiting HH-GLI pathway activity. Therefore, downstream inhibition of HH-GLI signaling may be a promising therapeutic strategy for HNSCC.
\end{abstract}

Keywords: hedgehog signaling; head and neck cancer; GLI; GANT61; LiCl; GSK3 $\beta$

\section{Introduction}

Head and neck squamous cell carcinoma (HNSCC) encompasses tumors arising in the oral cavity, larynx, nasopharynx, oropharynx, hypopharynx, and salivary glands, with an annual incidence of around 880,000 new cases worldwide and around 450,000 deaths [1]. HNSCC has high mortality, since it is usually diagnosed when the disease is locally advanced [2]. Major risk factors are tobacco and alcohol consumption and occupational risks (exposure to wood dust, acid mist, asbestos or solvents in the textile and wood industry) [3]. Infection with human papilloma virus 16 (HPV16) has been determined as an independent risk factor, and the affected individuals are usually younger and non-smokers [4]. Recently, the incidence of tobacco- and alcohol-associated HNSCC has decreased, 
but HPV-associated HNSCC has increased in developed countries [5]. In Croatia, the majority of HNSCC cases are still HPV-negative and are associated with tobacco and alcohol consumption $[6,7]$. In HNSCC, cancer stem cells (CSC) are considered to be responsible for tumor initiation, progression, and metastasis, but also for drug resistance and recurrence. Signaling pathways often activated in CSC include the Hedgehog-Gli (HH-GLI), WNT, EGFR, and NOTCH pathways [8]. Treatment of the early stages of HNSCC includes surgery or radiotherapy, while advanced stages are resected surgically and treated with adjuvant radio- or chemoradiotherapy. Immunotherapy has also been implemented for therapy of recurrent or metastatic disease; however, the efficacy is limited due to primary or acquired tumor resistance $[9,10]$. To bypass potential tumor resistance, other potential molecular targets are being investigated, such as the phosphoinositol 3 kinase (PI3K) pathway, human growth hormone (HGF) pathway, NOTCH signaling pathway, HH-GLI signaling pathway, and angiogenesis regulated by vascular endothelial growth factor (VEGF) signaling [10].

The HH-GLI signaling pathway is a developmental pathway, mostly inactive in the adult organism except in stem cell maintenance and wound healing. The main components are the hedgehog $(\mathrm{HH})$ ligands (Sonic hedgehog, SHH, Indian hedgehog, IHH, and Desert hedgehog, DHH). They bind to the transmembrane receptor patched (PTCH1), which releases its inhibitory effect on the co-receptor smoothened (SMO). This triggers a phosphorylation and ubiquitination cascade in the cytoplasm through several proteins, including beta-transducin repeat containing protein $1(\beta \operatorname{TrCP} 1)$, glycogen synthase kinase 3 beta (GSK3 $\beta$ ), protein kinase A (PKA), casein kinase 1 (CK1), and suppressor of fused (SUFU), which ultimately regulate the processing of glioma-associated oncogene homolog (GLI) proteins. The full-length versions of GLI1-3 proteins are transcriptional activators, while the truncated versions of GLI2-3 are transcriptional repressors. GLI proteins regulate the transcription of many genes involved in proliferation, differentiation, cell cycle regulation, stemness, epithelial-mesenchymal transition (EMT), angiogenesis, and invasiveness, as well as pathway autoregulation through PTCH1 and GLI1 [11].

Most of the studies dealing with the role of the HH-GLI pathway in HNSCC used immunohistochemical staining as the method of choice. In most of them, only GLI1 of the three GLI proteins was stained, and its nuclear localization was associated with metastasis, poor survival, tumor size, and recurrence [12-15]. GLI1 nuclear expression was also shown to be a predictive biomarker for response to chemoradiation in esophageal cancer [16]. Staining of other proteins of the pathway, namely, PTCH1, SMO, GLI2, and SHH, has also been reported [7,17-20], and one study demonstrated that HH-GLI pathway proteins show a progressive increase in expression from healthy mucosa, through dysplastic tissue, to carcinoma [21].

In vitro studies on HNSCC cell lines focus mostly on the inhibition of the membrane part of the pathway, protein SMO. Cyclopamine, an SMO inhibitor, can inhibit the growth of esophageal cancer In vitro [22], and it can sensitize HNSCC cells to cisplatin and docetaxel [23]. Vismodegib, another SMO inhibitor, sensitizes HNSCC cells to radiation therapy [24].

Almost all studies examine the role of GLI1 as the main marker of the HH-GLI pathway activity, with only a few examining the roles of GLI2 and GLI3. HNSCC spheroid cultures demonstrate EMT, CSC-like phenotype, and upregulation of GLI1 and GLI2 genes [25]. Rodrigues et al. recently demonstrated that GLI3 is important in the CSC population of oral squamous cell carcinoma (OSCC) and is involved in cell proliferation, invasion, and stemness of these cells [26]. It is known that GLI proteins can be activated by non-canonical signaling and can bypass this upstream inhibition. Therefore, we decided to investigate downstream inhibitors in several HNSCC cell lines. We focused our research on two inhibitors, a direct GLI inhibitor GANT61, and lithium chloride (LiCl), a GSK3 $\beta$ inhibitor. GSK3 $\beta$ can have a stimulatory or inhibitory effect on GLI proteins, depending on its phosphorylation status. In non-stimulated cells, GSK3 $\beta$ (phosphorylated at Tyr216) is constitutively active and phosphorylates a range of targets to keep them in an off-state [27]. $\mathrm{LiCl}$ promotes phosphorylation of GSK3 $\beta$ at the Ser9 position, leading to the phosphorylation of GLI proteins and their processing into repressor forms and/or degradation [28]. 


\section{Results}

\subsection{The HH-GLI Signaling Pathway Is Active in HNSCC Cell Lines}

HH-GLI signaling pathway genes PTCH1, GLI1, GLI2, and GLI3 are expressed in all analyzed HNSCC cell lines. Out of the three GLI genes, GLI3 shows the strongest expression in all analyzed cell lines (Figure 1A). The same expression pattern is visible at the protein level. The full-length GLI3 protein (GLI3FL) shows the strongest expression of all GLI proteins (Figure 1B). The calculated mass of the GLI1 protein is $118 \mathrm{kDa}$ [29], However, the full-length size of GLI1 has been shown to migrate to $160 \mathrm{kDa}$ [30], and we detected a signal at this size only in the A253 line, while it is very faint in other lines. For GLI2, we could not detect the protein in its full-length form of $185 \mathrm{kDa}$ nor the repressor form at $80 \mathrm{kDa}$, but only a non-specific band around $100 \mathrm{kDa}$. The PTCH1 protein was detected in all cell lines, in some more strongly than others (Figure 1B). Therefore, we can conclude that the HH-GLI signaling pathway is active in all studied HNSCC cell lines.
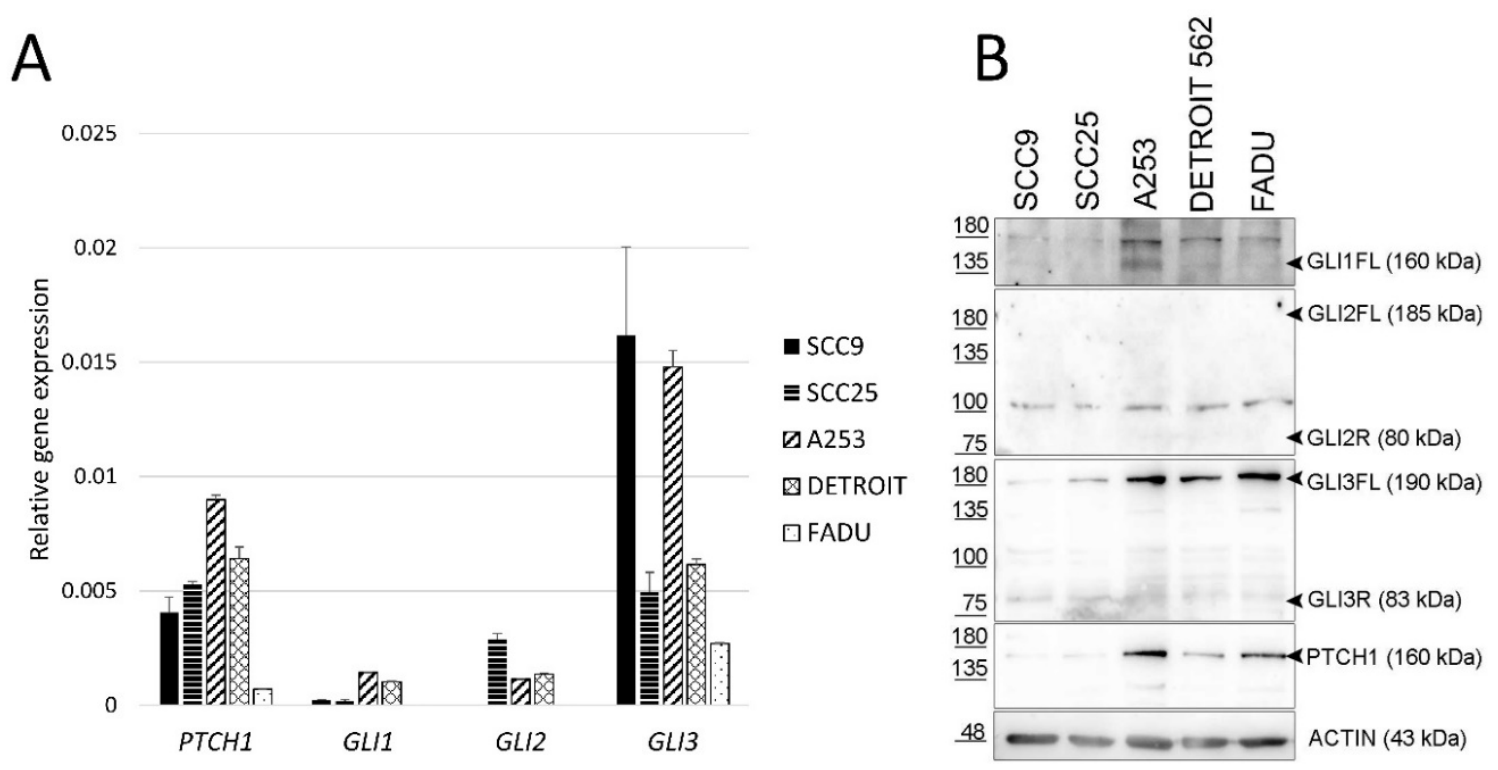

Figure 1. Gene and protein expression of HH-GLI pathway components in HNSCC. (A) Relative gene expression of PTCH1, GLI1, GLI2, and GLI3 determined by quantitative Real-Time Polymerase Chain Reaction (qRT-PCR). Gene expression is shown relative to the level of the housekeeping gene RPLP0. (B) Protein expression determined by Western blot. FL refers to the full-length protein (activator form), while $\mathrm{R}$ refers to the repressor form.

\subsection{HNSCC Cell Lines Respond to Downstream Inhibition More Efficiently Than to Upstream Inhibition}

To determine if the HH-GLI pathway activity can be modified in these lines, the cell lines were treated with three different HH-GLI pathway inhibitors: cyclopamine (1.25-10 mM), GANT61 (5-25 $\mu \mathrm{M})$, and lithium chloride $(\mathrm{LiCl})(5-40 \mathrm{mM})$. Cyclopamine acts on the membrane part of the $\mathrm{HH}-\mathrm{GLI}$ pathway, $\mathrm{LiCl}$ modifies the activity of a cytoplasmatic regulatory kinase GSK $3 \beta$, while GANT61 inhibits GLI proteins. In four out of five cell lines, GANT61 has the strongest inhibitory effect on cell proliferation, followed by $\mathrm{LiCl}$, while cyclopamine shows the weakest or no effect (Supplementary Figure S1). The only exception is the hypopharyngeal squamous cell carcinoma cell line $\mathrm{FaDu}$, which is the most responsive to $\mathrm{LiCl}$ inhibition, followed by cyclopamine, while GANT61 shows the weakest effect. Median lethal dose (LD50) values were determined for all tested cell lines using the Prism 8 program (GraphPad Software, San Diego, CA, USA), and the summary results are presented in Table 1. Based on these results, 5 and $10 \mu \mathrm{M}$ GANT61 and 10 and $20 \mathrm{mM} \mathrm{LiCl}$ were used in the subsequent experiments for all cell lines. Cyclopamine was not tested further as its effects were very weak for these cell lines compared to GANT61 and $\mathrm{LiCl}$. The doses of cyclopamine that would 
be required to achieve the LD50 values were close to the concentrations that induce the non-specific toxicity independent of the HH-GLI pathway [31].

Table 1. Median lethal dose (LD50). LD50 values for each of the tested compounds.

\begin{tabular}{ccccc}
\hline Line & Tissue & Cyclopamine $(\mu \mathbf{M})$ & LiCl $(\mathbf{m M})$ & GANT61 $(\boldsymbol{\mu M})$ \\
\hline SCC9 & Tongue & $>10$ & 11.45 & $>25$ \\
SCC25 & Tongue & 9.51 & 15.24 & 6.83 \\
A253 & Salivary gland & 6.48 & 14.56 & 8.36 \\
DETROIT562 & Pharynx & $>10$ & 11.4 & 9.54 \\
FADU & Hypopharynx & $>10$ & 5.53 & 19.7 \\
\hline
\end{tabular}

To check if the pathway activity is functionally inhibited by these treatments, target gene PTCH1 expression was determined with qRT-PCR. GANT61 treatment significantly downregulates the expression of the PTCH1 gene in three HNSCC cell lines (SCC9, SCC25, A253). LiCl treatment downregulates the expression of PTCH1 in all lines except Detroit562 (Figure 2).

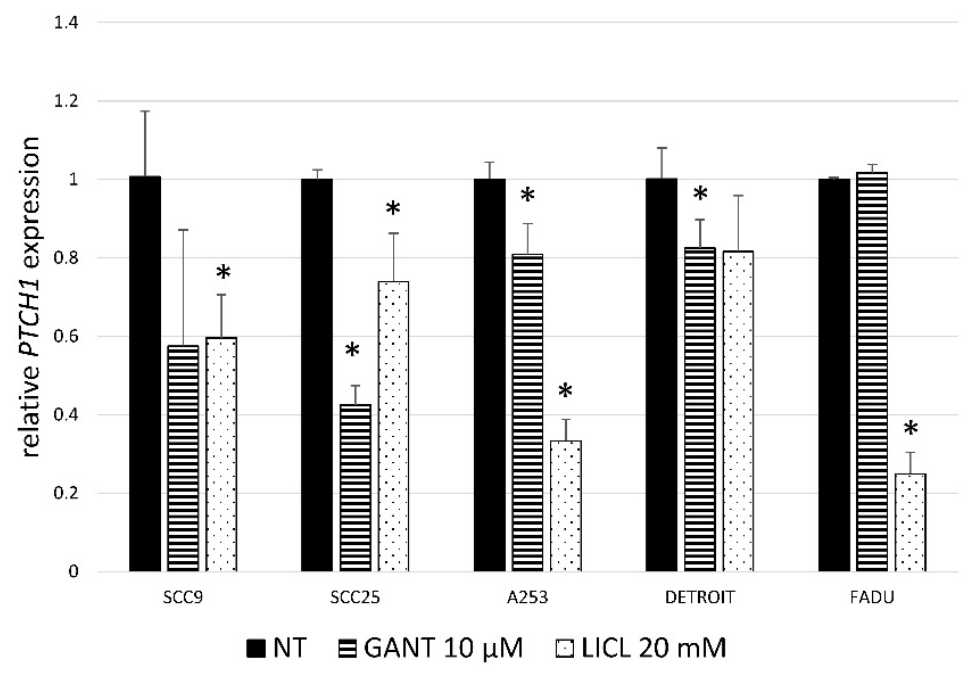

Figure 2. Relative gene expression of PTCH1. PTCH1, the target gene of the HH-GLI signaling pathway, 24h after GANT61 or $\mathrm{LiCl}$ treatment. LiCl downregulates PTCH1 expression in 4/5 HNSCC cell lines, and GANT61 in 3/5 lines. * denotes a statistically significant difference from non-treated (NT) cells $(p<0.05)$.

\subsection{GANT61 and LiCl Regulate GLI3 Protein Levels in HNSCC}

The levels of GLI1 and GLI3 expression were determined after inhibition with GANT61 or LiCl to determine the effect of inhibition on the balance of GLI activators and repressors. The GLI3 protein was the most consistently expressed of all three GLI proteins. To our knowledge, there are no reported isoforms of GLI3 in the literature apart from the full length (GLI3FL) at $190 \mathrm{kDa}$, and the repressor form (GLI3R) at $83 \mathrm{kDa}$. The GLI3 protein was present in the full-length form in all examined cell lines, suggesting it acts as the pathway activator in HNSCC cell lines. GLI3R was found strongly expressed in two HNSCC lines, and weakly expressed in three HNSCC lines. In SCC9, SCC25, and Detroit562 cell lines, GLI3FL was downregulated after GANT61 and LiCl treatment. Interestingly, an additional, yet unidentified band around $120 \mathrm{kDa}$ was detected in all five HNSCC cell lines after GANT61 treatment. In the untreated cells, the band is not detected in two lines, weakly detected in one, and strongly in two lines. Upon GANT61 treatment, it is upregulated in all cell lines, and in the case of SCC9 and A253 by LiCl treatment as well (Figure 3A). The GLI1 protein was continuously poorly expressed and barely detectable in all tested HNSCC cell lines (Figure 3B). To determine if the unidentified GLI3 band was specific, we performed immunoprecipitation of GANT61-treated lines A253 and FaDu with a 
different GLI3 antibody (AF-3690, R\&D) followed by direct gel staining with Coomassie. This specific antibody is not validated for Western blot application, only for immunoprecipitation, so to avoid possible non-specific staining during Western blot, the detection of the proteins was done directly in the gel. The band was not as strong as in the Western blot, but a faint line of the unidentified GLI3 band could be detected in both cell lines (Figure 3C). Immunoprecipitation also detected GLI3FL very clearly, and GLI3R faintly, corresponding to the Western blot results.

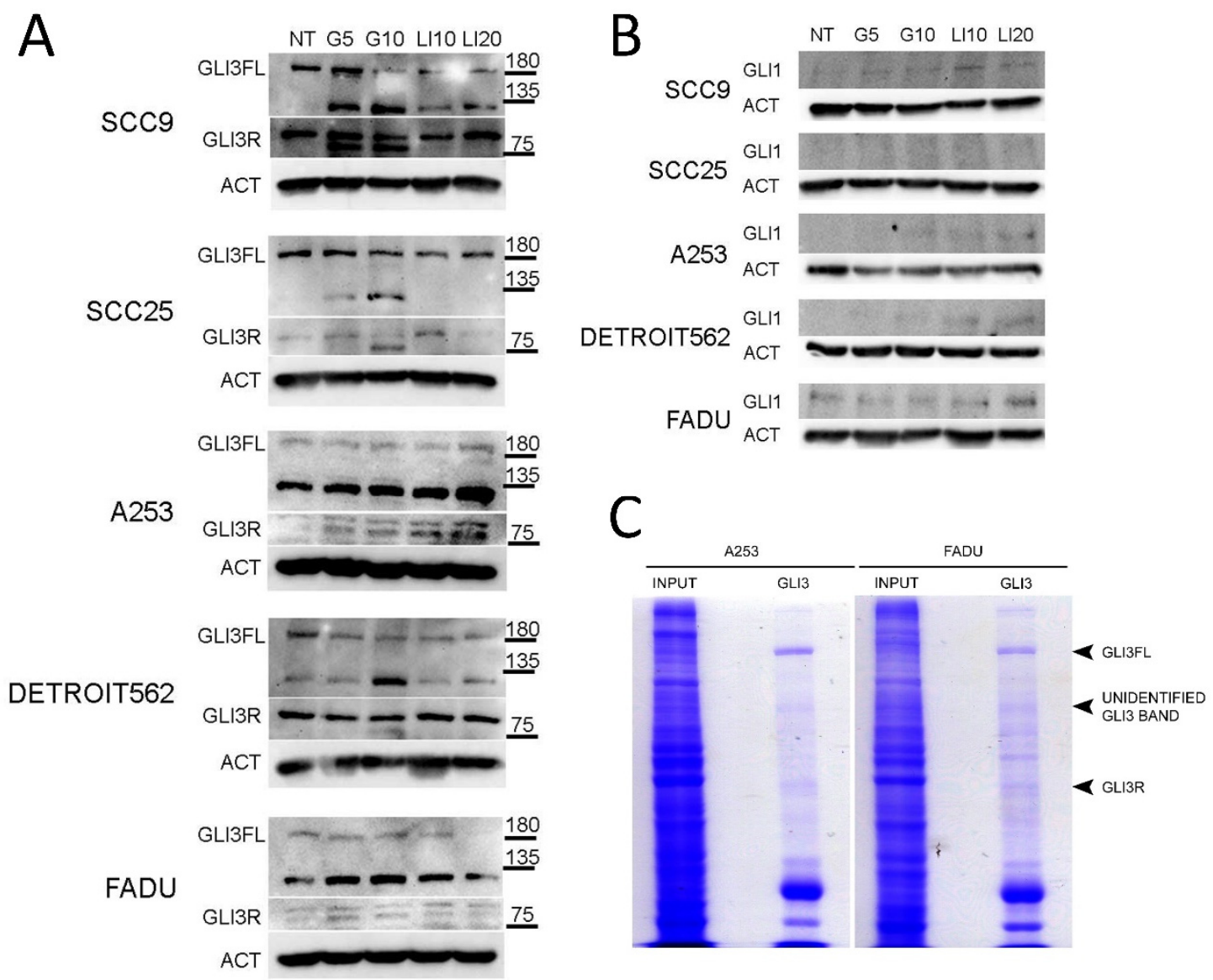

Figure 3. The effect of GANT61 and $\mathrm{LiCl}$ treatment on the expression of GLI proteins. (A) GLI3 and (B) GLI1 protein expression after treatment with HH-GLI pathway inhibitors GANT61 and LiCl

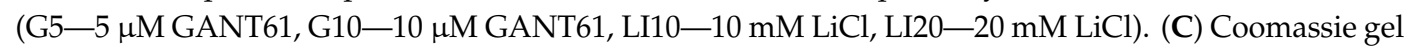
stain of immunoprecipitation with GLI3 antibody (AF-3690, R\&D) for two HNSCC cell lines treated with GANT61. In both cell lines, the IP successfully detects the GLI3FL and GLI3R bands. The unidentified GLI3 band is also faintly detected in both tested cell lines.

\subsection{The Effect of LiCl Inhibition Is Mediated by GLI3 Processing by GSK3 $\beta$}

To test the effect of $\mathrm{LiCl}$ on the HH-GLI signaling pathway, phosphorylation of GSK3 $\beta$ was investigated by Western blot. It is known that $\mathrm{LiCl}$ treatment increases the inhibitory Ser9 phosphorylation of GSK3 $\beta$. In all HNSCC cell lines, $\mathrm{LiCl}$ increased the Ser9 phosphorylated form of the GSK3 $\beta$ protein, while the total GSK3 $\beta$ levels remained unchanged. This phosphorylation affects GSK3 $\beta$ activity, leading to increased processing of GLI3 from full length to repressor form. This effect can be seen as reduced GLI3FL levels in all HNSCC cell lines, but the increase of GLI3R is detected only in some lines (Figure 4). GANT61 treatment acts directly on the level of the GLI3 protein, also shifting the balance of activator/repressor forms toward the repressor, thus inhibiting pathway activity. 


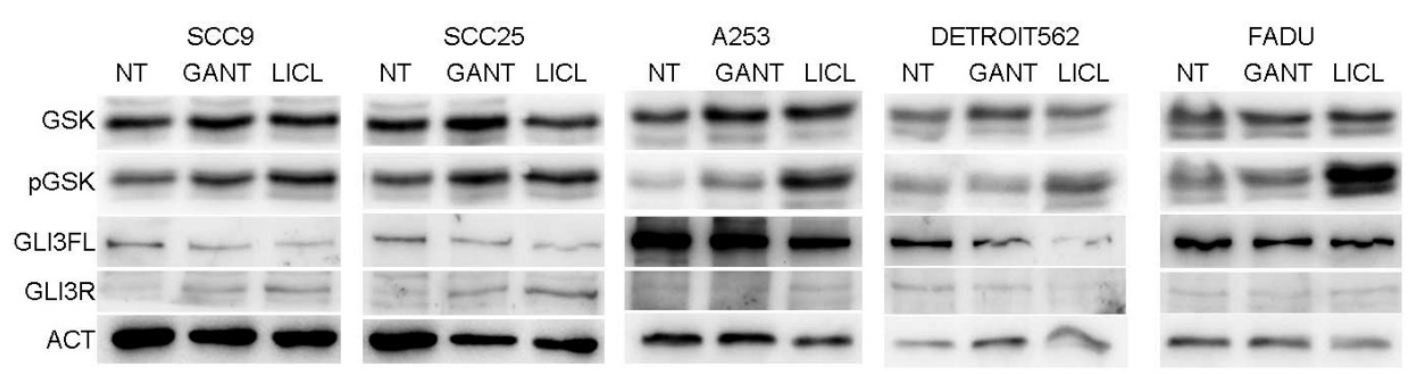

Figure 4. The role of GSK3 $\beta$ phosphorylation in GLI3 protein activity. Western blot showing phosphorylation of GSK3 $\beta$ (pGSK) compared to total GSK levels in non-treated (NT) or GANT61 $(10 \mu \mathrm{M})$ or LiCL $(20 \mathrm{mM})$ treatment. All HNSCC cell lines show an increase in GSK3 $\beta$ phosphorylation with $\mathrm{LiCl}$, and three of the lines also with GANT61 treatment. This effect is closely followed by the downregulation of GLI3FL.

\subsection{Downstream Inhibition Affects Colony Forming and Wound Closure Capabilities of HNSCC Cell Lines}

To test the colony forming ability of HNSCC cell lines after GANT61 or LiCl treatment, 1000 cells were plated in a 6-well and maintained for 14 days in medium containing different concentrations of GANT61 and LiCl. All the cell lines showed a dose-dependent decrease in colony forming ability after treatment with either compound. In most cell lines GANT61 was more effective, but in Detroit562 and $\mathrm{FaDu}$ lines, $\mathrm{LiCl}$ was more effective (Figure 5).
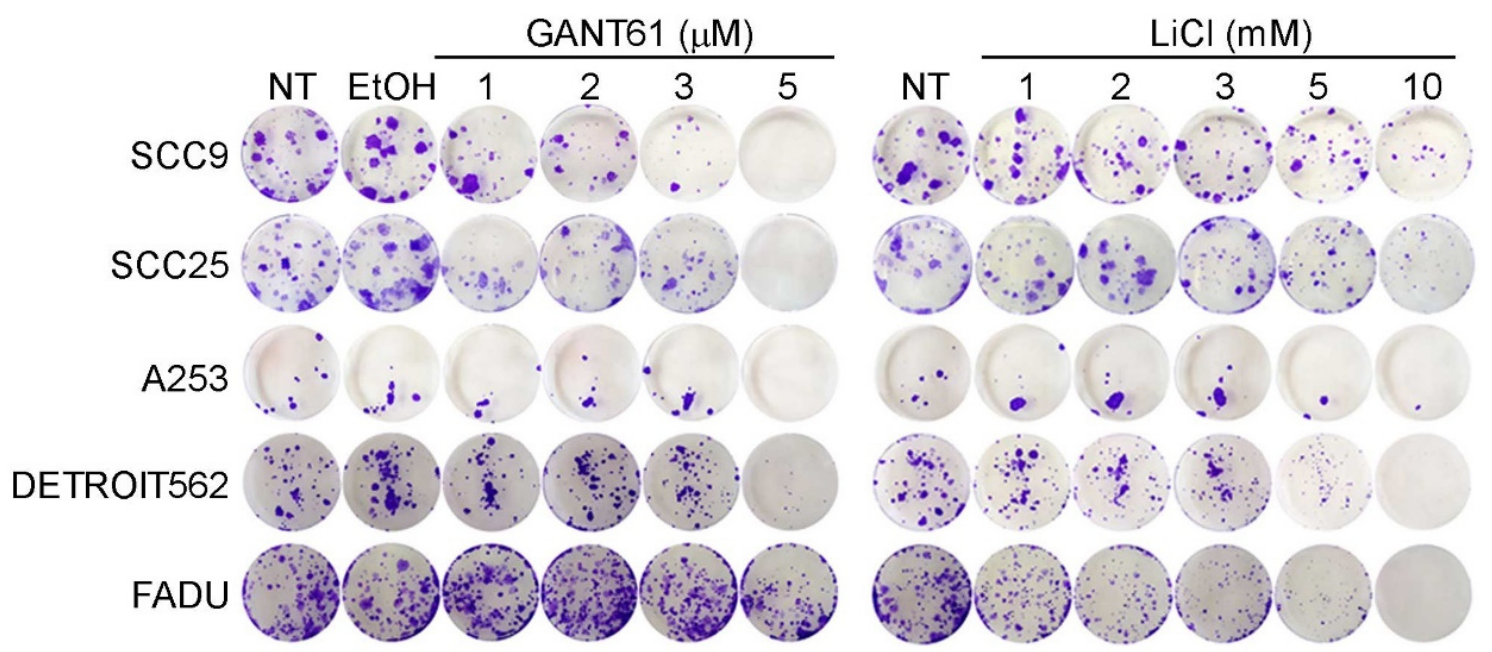

Figure 5. Colony forming assay on HNSCC cell lines. All cell lines show a dose-dependent decrease in colony forming ability with both GANT61 and $\mathrm{LiCl}$. EtOH - vehicle control.

Wound healing assay was used to examine the proliferative and migratory ability of cells (Figure 6A). In all tested HNSCC cell lines, wound closure was inhibited by $\mathrm{LiCl}$, while GANT61 treatment slightly enhanced wound closure only in Detroit562 and FaDu cells (Figure 6B). As both compounds inhibit the proliferation of these cells, but the wound closure is inhibited only with $\mathrm{LiCl}$, it is likely that this effect is due to the change in the migratory ability of cells, but this would need to be confirmed by other assays, such as the Transwell assay. This suggests that in HNSCC cell lines, GLI proteins generally do not affect the migration of cells. Migratory ability of cells is not regulated by the HH-GLI signaling pathway, but rather by a different GSK3 $\beta$-triggered mechanism, since LiCl treatment affects the migratory potential of these cells. 
A

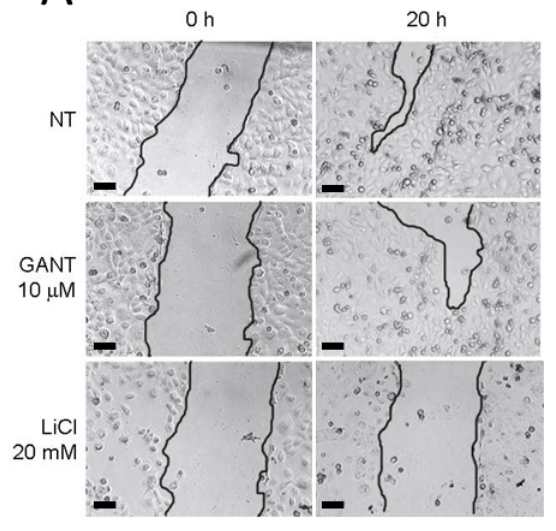

B

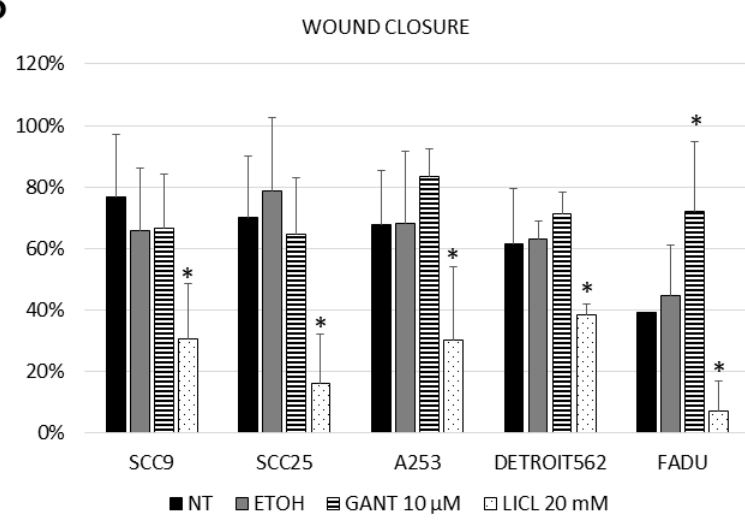

Figure 6. The wound healing assay. (A) Digital photographs of wound healing processes (scale bar $=200 \mu \mathrm{m}$ ). (B) Quantification of wound closure. GANT61 inhibition has almost no effect on the wound closure compared to the non-treated cells (NT), with the exception of a slight increase in wound closure for the Detroit562 and $\mathrm{FaDu}$ cell lines. $\mathrm{LiCl}$ treatment inhibits wound closure capability in all cell lines. EtOH—vehicle control. * denotes statistically significant difference from non-treated (NT) cells $(p<0.05)$.

\section{Discussion}

In this work we demonstrate for the first time the effect of downstream HH-GLI pathway inhibitors GANT61 and $\mathrm{LiCl}$ on HNSCC cell lines. It has been demonstrated previously that the HH-GLI signaling pathway is upregulated and activated in HNSCC $[12-14,18,20]$. The majority of these studies, however, focused only on the GLI1 transcription factor, with few of them examining GLI2, and none of them testing for GLI3 staining. Similarly, in vitro studies on HNSCC cell lines focused mostly on SMO inhibition, with no studies examining potential non-canonical downstream activation of GLI transcription factors and downstream inhibition.

In our set of five HNSCC cell lines, the most uniformly expressed GLI protein is GLI3, while GLI2 is undetectable, and GLI1 is poorly detectable at both mRNA and protein levels. In this study we have demonstrated by the MTT assay that GANT61 and LiCl show much stronger growth inhibition of HNSCC cells than previously used cyclopamine. Different cell lines respond slightly differently, with most of them showing stronger sensitivity to GANT61 and only one line, FaDu, to LiCl. The colony forming ability of HNSCC cell lines is reduced after GANT61 or LiCl treatment, but the wound closure is affected only by $\mathrm{LiCl}$ and not by GANT61 treatment. Since $\mathrm{LiCl}$ regulates GSK3 $\beta$ activity, and this protein regulates many other targets except GLI (e.g., $\beta$-catenin, p53, AP-2, NF-kB) [27], it is likely that the effect on wound closure is mediated by a different mechanism and not by GLI proteins. Both GANT61 and LiCl treatment downregulate the levels of the GLI3FL protein and upregulate the GLI3R form, suggesting proteolytic processing and inhibition of the HH-GLI pathway through GLI3 activator/repressor balance. GLI1 remained mostly unaffected by either treatment, again confirming GLI3 as the pathway regulator. Our findings are supported by a recent paper by Rodrigues et al., who demonstrated a crucial role of GLI3 in cell proliferation and invasion of the OSCC cancer stem cell (CD44high) population [26]. To determine the effect of LiCl on GLI3 levels, the ratios of GSK3 $\beta$ and Ser9 phosphorylated GSK3 $\beta$ (pGSK3 $\beta$ ) were examined after GANT61 and LiCl treatment. LiCl generally increases GSK3 $\beta$ phosphorylation, resulting in downregulation of GLI3FL and upregulation of GLI3R. This mechanism has been demonstrated previously in colon cancer cell lines, and it occurs in tumors where the GSK3 $\beta$ activator (Tyr216 pGSK3 $\beta$ ) and inhibitor (Ser9 pGSK3 $\beta$ ) are in disbalance, with Tyr216 pGSK3 $\beta$ acting as an oncogene [28]. Recently, Nayak et al. showed the effect of nanoquinacrine (NQC) on GSK3 $\beta$ in CSC isolated from the SCC 25 line: upon NQC treatment, total GSK3 $\beta$ levels are increased, while pGSK3 $\beta$ levels are decreased, as are GLI1 levels [32]. The effect we detected for LiCl treatments seems to work in the opposite manner: $\mathrm{LiCl}$ leads to phosphorylation of GSK3 $\beta$ at Ser9, leading to 
increased processing of GLI3FL to GLIR. The difference observed between the two studies may be due to the pre-selection of the CSC population in the case of the NQC study. This may have selected for cells with different levels of GSK3 $\beta$ and GLI proteins than the levels we observed in the unselected population of the same cell line. In the CSC population, the Ser9 pGSK3 $\beta$ is far more expressed than the total GSK3 $\beta$, while in this case the distribution is the opposite. Interestingly, GANT61 treatment, and in some cases $\mathrm{LiCl}$ treatment, induced an unidentified GLI3 band on Western blots. We could confirm this by immunoprecipitation with an IP-specific antibody followed by Coomassie stain, but the intensity of the band was not sufficient for fragment identification by mass spectrometry. Therefore, we cannot speculate on the nature or role of the detected GLI3 band, but only demonstrate its upregulation after GANT61 treatment. Taken together, all these results show that the HH-GLI signaling pathway is affected by inhibitors acting downstream of SMO. The major pathway effector in these cell lines was shown to be GLI3, which is present in the full-length form in proliferating cells, but is processed into the repressor form when cells are treated with GANT61 or LiCl. This suggests that downstream pathway inhibitors may be more effective in potential future clinical use for treatment of HNSCC, especially in combination with other signaling pathways often found upregulated in HNSCC.

\section{Materials and Methods}

\subsection{Cell Culture and Cell Assays}

HNSSC cell lines SCC9, SCC25, A253, Detroit562, and FaDu were purchased from the ATCC (no. TCP-1012, Manassas, VA, USA) and maintained in the recommended media. A-253 was maintained in McCoy's 5A medium (Merck KGaA, Darmstadt, Germany), SCC9 and SCC25 in DMEM:HAM'S=1:1 (Dulbecco's Modified Eagle Medium: Ham's F12) medium (Merck KGaA, Darmstadt, Germany), and FaDu and Detroit562 in EMEM (Eagle's Minimum Essential Medium) medium (Merck KGaA, Darmstadt, Germany), all supplemented with 10\% FBS (Fetal Bovine Serum, Merck KGaA, Darmstadt, Germany). The cell lines are derived from different anatomical sites: SCC9 and SCC25 originate from the oral cavity (tongue), FaDu from the hypopharynx, Detroit562 from the metastatic site (pleural effusion of pharyngeal cancer), and A253 from the salivary gland. All the cell lines are established and frequently used models of HNSCC, and were purchased as an HNSCC panel designed by the ATCC. According to the available data, all these lines are HPV-negative.

For MTT (3-(4,5-Dimethylthiazol-2-yl)-2,5-Diphenyltetrazolium Bromide) assays, cells were plated at $2 \times 10^{3}$ cells/well in 96-well plates and treated with a range of concentrations of different HH-GLI pathway inhibitors: cyclopamine 1.25-10 $\mu \mathrm{M}$ (Selleck Chemicals, Houston, TX, USA), GANT61 5-25 $\mu \mathrm{M}$ (Selleck Chemicals, Houston, TX, USA), and LiCl 5-40 mM (Kemika, Zagreb, Croatia) for 24-72 h, and cell viability was measured on LabsSystems Multiskan MS microplate reader (Thermo Fisher Scientific, Waltham, MA, USA) after incubation with MTT. The treatment was done in quadruplicate for each dose, and the experiment was repeated twice.

For colony forming assay, 1000 cells/well were plated in a 6-well plate, left to attach for $24 \mathrm{~h}$, and then treated with 1-5 $\mu \mathrm{M}$ GANT61 or 1-10 mM LiCl. Cells were kept in culture for 2 weeks to allow for colony formation, with media with compounds changed twice per week. Cells were then washed with PBS, fixed with $4 \%$ paraformaldehyde, and stained with crystal violet to visualize the colonies. The experiments were performed in triplicate.

For wound healing assay, $10^{5}$ cells/well were plated in 24-well plates and left for $24 \mathrm{~h}$ to attach. Two scratches per well were made with a $10 \mu \mathrm{L}$ pipette tip; cells were washed with PBS (Phosphate Buffered Saline) to remove floating cells and were treated with GANT61 or LiCl. Images of the scratch were taken immediately after washing with PBS and $24 \mathrm{~h}$ later at the same location. Eight images were taken for each treatment, and the images were processed using the MRI Wound Healing Tool plugin for FIJI [33] to calculate the wound area. The experiments were done in triplicate. 
For gene/protein extraction, cells were treated with 5 and $10 \mu \mathrm{M}$ GANT61, or 10 and $20 \mathrm{mM} \mathrm{LiCl}$ for $24 \mathrm{~h}$. Cells were collected by scraping with the cell scraper, washing in PBS, and collecting the cell pellet, which was used for either RNA or protein extraction.

\subsection{Quantitative Real-Time Polymerase Chain Reaction ( $q$ RT-PCR)}

RNA was extracted from cell pellets with TRIzol reagent (Invitrogen, Carlsbad, CA, USA) per the manufacturer's instructions. One microgram of RNA was reverse transcribed into cDNA using the High Capacity cDNA synthesis kit (Thermo Fisher Scientific, Waltham, MA, USA), and qRT-PCR was performed on the CFX-96 instrument (Bio-Rad Laboratories, Hercules, CA, USA) using SsoAdvanced SYBR Green (Bio-Rad Laboratories, Hercules, CA, USA). The expression of PTCH1, GLI1, GLI2, and GLI3 genes was measured as described previously [7], and the fold change was calculated relative to the RPLPO housekeeping gene.

\subsection{Western Blotting}

Total proteins were extracted by sonication in RIPA (Radioimmunoprecipitation assay buffer) buffer containing protease and phosphatase inhibitors, and the protein concentration was measured using the BCA (Bicinchonic Acid) kit (Thermo Fisher Scientific, Waltham, MA, USA); $40 \mu \mathrm{g}$ of protein was loaded on 7\% PAA (Polyacrylamide) gel. After electrophoresis, they were transferred to a nitrocellulose membrane (Amersham BioSciences, Little Chalfont, England, UK), blocked with 5\% milk and incubated with primary antibodies overnight. Antibodies used for detection were as follows: rabbit anti-GLI1 (Cell Signaling Technology, V812, 1:200, Danvers, MA, USA), mouse anti-GLI2 (Santa Cruz Biotechnology, sc-271786, 1:200, Dallas, TX, USA), rabbit anti-GLI3 (GeneTex GTX104362, 1:1000, Irvine, CA, USA). Actin (60008-1-Ig, ProteinTech, 1:4000, Rosemont, IL, USA) was used as a loading control. After washing in TBST (Tris-Buffered Saline, $0.1 \%$ Tween ${ }^{\circledR} 20$ Detergent), secondary antibodies HRP (Horseradish Peroxidase)-conjugated anti-rabbit (BD Pharmingen, 554021, 1:6000, San Jose, CA, USA) and anti-mouse (BD Pharmingen, 554002, 1:8000, San Jose, CA, USA) were applied for 1h at room temperature, washed, and visualized using SuperWest Signal Pico and Femto reagents (Thermo Fisher Scientific, Waltham, MA, USA) on Uvitec Image Alliance 4.7 instrument (UVItec, Cambridge, England, UK).

\subsection{Immunoprecipitation and Coomassie Staining}

For immunoprecipitation (IP), proteins were extracted from GANT61-treated FaDu and A253 cell lines using TENN buffer (50 mM Tris, 5 mM EDTA, $150 \mathrm{mM} \mathrm{NaCl}, 0.5 \%$ NP-40, pH 8.0) supplemented with protease inhibitors (Roche, Basel, Switzerland). Protein concentration was determined using the Pierce BCA Protein Assay Kit (Thermo Fisher Scientific, Waltham, MA, USA). Immunoprecipitation was performed using Protein G-coated Dynabeads (Life Technologies, Carlsbad, CA, USA) according to the manufacturer's instructions (Invitrogen, Rev. 005, Carlsbad, CA, USA). For Gli3 immunoprecipitation, $1000 \mu \mathrm{g}$ of proteins and $5 \mu \mathrm{g}$ of Gli3 antibody (AF-3690, R\&D Systems, Minneapolis, MN, USA) were used for each IP sample. Samples were incubated with the Dynabead-antibody complex overnight at $+4{ }^{\circ} \mathrm{C}$. Samples were eluted with $1 \times$ loading buffer and heated for $5 \mathrm{~min}$ at $95^{\circ} \mathrm{C}$ before electrophoresis in $7 \%$ PAA gel. After gel electrophoresis, the proteins were fixed in $50 \%(v / v)$ ethanol and $10 \%(v / v)$ acetic acid for $1 \mathrm{~h}$ at room temperature followed by further fixation in 50\% $(v / v)$ methanol and $10 \%(v / v)$ acetic acid overnight at $+4{ }^{\circ} \mathrm{C}$. The gels were stained in Coomassie Blue R250 (LKB Bromma, Bromma, Sweden) staining solution (3g/L Coomassie Blue R250, 45\% (v/v) methanol, 10\% (v/v) acetic acid in water) for $4 \mathrm{~h}$ with gentle agitation, and afterwards destained in 50\% $(v / v)$ methanol and $10 \%(v / v)$ acetic acid. The destaining solution was changed several times until the protein bands were completely visible. The gels were stored in $5 \%(v / v)$ acetic acid at $+4{ }^{\circ} \mathrm{C}$. 


\subsection{Statistical Analysis}

Normality of data distribution was tested using the D'Agostino-Pearson test. An independent samples t-test was used for comparing wound healing and gene expression between non-treated and treated cells. Two-tailed $p$ values $<0.05$ were considered statistically significant. Statistical analysis was performed using MedCalc v19.1.6 (MedCalc Software Ltd., Ostend, Belgium).

\section{Conclusions}

GANT61 and LiCl, downstream HH-GLI pathway inhibitors, inhibit the proliferation and colony forming capability of HNSCC cells. The upstream inhibitor cyclopamine, on the other hand, requires high doses to produce an effect on HNSCC cell lines. This suggests that the downstream components of HH-GLI signaling are activated at least partly non-canonically in HNSCC. Wound closure of HNSCC cells is not affected by GANT61 but it is reduced after $\mathrm{LiCl}$ treatment, suggesting that the effect of $\mathrm{LiCl}$ on wound closure is mediated through another pathway independent of HH-GLI. The main effector of HH-GLI signaling in HNSCC is the GLI3 protein, which is the most expressed of all three GLI proteins and is responsive to GANT61 and $\mathrm{LiCl}$ inhibition. $\mathrm{LiCl}$ increases the inhibitory Ser9 phosphorylation of GSK3 $\beta$, leading to increased processing of GLI3 from the full-length form to the repressor form, and inhibiting the pathway. Therefore, downstream inhibition of HH-GLI signaling in HNSCC may be a promising therapeutic strategy.

Supplementary Materials: The following are available online at http://www.mdpi.com/1422-0067/21/17/6410/s1, Figure S1: Results of the MTT assay.

Author Contributions: Conceptualization, V.Z., D.L. and M.S.; Data curation, P.O.; Formal analysis, P.O.; Funding acquisition, D.L. and M.S.; Investigation, V.Z., N.R., M.K., D.T. and V.M.; Project administration, S.L.; Resources, V.Z. and S.L.; Supervision, D.L. and M.S.; Validation, N.R., M.K., D.T., V.M. and M.S.; Visualization, P.O. and M.S.; Writing—original draft, V.Z., N.R., D.L. and M.S.; Writing—review \& editing, M.K., D.T., V.M., P.O. and S.L. All authors have read and agreed to the published version of the manuscript.

Funding: This research was funded by the grants of the Croatian Science Foundation no. HRZZ-IP-2016-06-1268, no. HRZZ-IP-2018-01-4889.

Acknowledgments: The authors wish to thank the Croatian Society of Head and Neck Diseases of Slavonia and Baranja for the kind donation of resources for this study.

Conflicts of Interest: The authors declare no conflict of interest.

\section{Abbreviations}

$\begin{array}{ll}\text { HH-GLI } & \text { Hedgehog-Gli } \\ \text { LiCl } & \text { Lithium chloride } \\ \text { HNSCC } & \text { Head and neck squamous cell carcinoma } \\ \text { HPV16 } & \text { Human papilloma virus } 16 \\ \text { CSC } & \text { Cancer stem cells } \\ \text { EGFR } & \text { Epidermal growth factor receptor } \\ \text { PI3K } & \text { Phosphoinositol 3 kinase } \\ \text { VEGF } & \text { Vascular endothelial growth factor } \\ \text { PTCH1 } & \text { Patched 1 } \\ \text { HH } & \text { Hedgehog } \\ \text { SMO } & \text { Smoothened } \\ \beta \text { TrCP1 } & \text { Beta-transducin repeat containing protein 1 } \\ \text { GSK3 } \beta & \text { Glycogen synthase 3 beta } \\ \text { PKA } & \text { Protein kinase A } \\ \text { SUFU } & \text { Suppressor of fused } \\ \text { CK1 } & \text { Casein kinase 1 } \\ \text { GLI } & \text { Glioma-associated oncogene homolog } \\ \text { EMT } & \text { Epithelial-mesenchymal transition }\end{array}$




$\begin{array}{ll}\text { NQC } & \text { Nanoquinacrine } \\ \text { DMEM:HAM'S } & \text { Dulbecco's Modified Eagle Medium: Ham's F12 } \\ \text { EMEM } & \text { Eagle's Minimum Essential Medium } \\ \text { FBS } & \text { Fetal bovine Serum } \\ \text { MTT } & \text { 3-(4,5-Dimethylthiazol-2-yl)-2,5-Diphenyltetrazolium Bromide } \\ \text { PBS } & \text { Phosphate Buffered Saline } \\ \text { RIPA } & \text { Radioimmunoprecipitation assay buffer } \\ \text { BCA } & \text { Bicinchonic Acid } \\ \text { PAA } & \text { Polyacrylamide } \\ \text { TBST } & \text { Tris-Buffered Saline, 0.1\% Tween } R 20 \text { Detergent } \\ \text { HRP } & \text { Horseradish Peroxidase } \\ \text { TENN } & 50 \text { mM Tris, } 5 \text { mM EDTA, } 150 \mathrm{mM} \mathrm{NaCl,} \mathrm{0.5 \%} \mathrm{NP-40,} \mathrm{pH} 8.0\end{array}$

\section{References}

1. Bray, F.; Ferlay, J.; Soerjomataram, I.; Siegel, R.L.; Torre, L.A.; Jemal, A. Global cancer statistics 2018: GLOBOCAN estimates of incidence and mortality worldwide for 36 cancers in 185 countries. CA A Cancer J. Clin. 2018, 68, 394-424. [CrossRef] [PubMed]

2. Jou, A.; Hess, J. Epidemiology and Molecular Biology of Head and Neck Cancer. Oncol. Res. Treat. 2017, 40, 328-332. [CrossRef] [PubMed]

3. Elkashty, O.A.; Ashry, R.; Tran, S.D.; Elkashty, O. Head and neck cancer management and cancer stem cells implication. Saudi Dent. J. 2019, 31, 395-416. [CrossRef] [PubMed]

4. Gillison, M.L.; D’Souza, G.; Westra, W.; Sugar, E.; Xiao, W.; Begum, S.; Viscidi, R. Distinct Risk Factor Profiles for Human Papillomavirus Type 16-Positive and Human Papillomavirus Type 16-Negative Head and Neck Cancers. J. Natl. Cancer Inst. 2008, 100, 407-420. [CrossRef]

5. Chaturvedi, A.K.; Engels, E.A.; Pfeiffer, R.M.; Hernandez, B.Y.; Xiao, W.; Kim, E.; Jiang, B.; Goodman, M.T.; Sibug-Saber, M.; Cozen, W.; et al. Human Papillomavirus and Rising Oropharyngeal Cancer Incidence in the United States. J. Clin. Oncol. 2011, 29, 4294-4301. [CrossRef]

6. Božinović, K.; Sabol, I.; Rakusic, Z.; Jakovčević, A.; Šekerija, M.; Lukinović, J.; Prgomet, D.; Grce, M. HPV-driven oropharyngeal squamous cell cancer in Croatia - Demography and survival. PLoS ONE 2019, 14, e0211577. [CrossRef]

7. Leović, D.; Sabol, M.; Ozretic, P.; Musani, V.; Car, D.; Marjanovic, K.; Zubcic, V.; Sabol, I.; Sikora, M.; Grce, M.; et al. Hh-Gli signaling pathway activity in oral and oropharyngeal squamous cell carcinoma. Head Neck 2011, 34, 104-112. [CrossRef]

8. Chen, D.; Wang, C.-Y. Targeting cancer stem cells in squamous cell carcinoma. Precis. Clin. Med. 2019, 2, 152-165. [CrossRef]

9. Cristina, V.; Herrera-Gómez, R.G.; Szturz, P.; Espeli, V.; Siano, M. Immunotherapies and Future Combination Strategies for Head and Neck Squamous Cell Carcinoma. Int. J. Mol. Sci. 2019, 20, 5399. [CrossRef]

10. Bowles, D.W.; McDermott, J.D.; Jimeno, A. Novel treatments for head and neck squamous cell carcinoma: Preclinical identification and clinical investigation. Future Oncol. 2014, 10, 1065-1080. [CrossRef]

11. Sabol, M.; Trnski, D.; Musani, V.; Ozretic, P.; Levanat, S. Role of GLI Transcription Factors in Pathogenesis and Their Potential as New Therapeutic Targets. Int. J. Mol. Sci. 2018, 19, 2562. [CrossRef] [PubMed]

12. Chung, C.H.; Dignam, J.J.; Hammond, M.E.; Klimowicz, A.C.; Petrillo, S.K.; Magliocco, A.; Jordan, R.; Trotti, A.; Spencer, S.; Cooper, J.S.; et al. Glioma-Associated Oncogene Family Zinc Finger 1 Expression and Metastasis in Patients With Head and Neck Squamous Cell Carcinoma Treated With Radiation Therapy (RTOG 9003). J. Clin. Oncol. 2011, 29, 1326-1334. [CrossRef] [PubMed]

13. Fan, H.-X.; Wang, S.; Zhao, H.; Liu, N.; Chen, D.; Sun, M.; Zheng, J. Sonic hedgehog signaling may promote invasion and metastasis of oral squamous cell carcinoma by activating MMP-9 and E-cadherin expression. Med. Oncol. 2014, 31, 1-8. [CrossRef] [PubMed]

14. Wang, Y.-F.; Chang, C.-J.; Lin, C.-P.; Chang, S.-Y.; Chu, P.-Y.; Tai, S.-K.; Li, W.-Y.; Chao, K.C.; Chen, Y.-J. Expression of hedgehog signaling molecules as a prognostic indicator of oral squamous cell carcinoma. Head Neck 2012, 34, 1556-1561. [CrossRef] [PubMed] 
15. Yang, Z.; Cui, Y.; Ni, W.; Kim, S.-H.; Xuan, Y. Gli1, a potential regulator of esophageal cancer stem cell, is identified as an independent adverse prognostic factor in esophageal squamous cell carcinoma. J. Cancer Res. Clin. Oncol. 2016, 143, 243-254. [CrossRef] [PubMed]

16. Wadhwa, R.; Wang, X.; Baladandayuthapani, V.; Liu, B.; Shiozaki, H.; Shimodaira, Y.; Lin, Q.; Elimova, E.; Hofstetter, W.L.; Swisher, S.G.; et al. Nuclear expression of Gli-1 is predictive of pathologic complete response to chemoradiation in trimodality treated oesophageal cancer patients. Br. J. Cancer 2017, 117, 648-655. [CrossRef] [PubMed]

17. Chen, G.; Yan, M.; Li, R.R.; Chen, W.T. Sonic Hedgehog Signalling Activation Contributes to ALCAM Over-Expression and Poor Clinical Outcome in Patients with Oral Squamous Cell Carcinoma. Chin. J. Dent. Res. 2018, 21, 31-40.

18. Dimitrova, K.; Stoehr, M.; Dehghani, F.; Dietz, A.; Wichmann, G.; Bertolini, J.; Mozet, C. Overexpression of the Hedgehog Signalling Pathway in Head and Neck Squamous Cell Carcinoma. Onkologie 2013, 36, 1. [CrossRef]

19. Richtig, G.; Aigelsreiter, A.M.; Asslaber, M.; Weiland, T.; Pichler, M.; Eberhard, K.; Sygulla, S.; Schauer, S.; Hoefler, G.; Aigelsreiter, A. Hedgehog pathway proteins SMO and GLI expression as prognostic markers in head and neck squamous cell carcinoma. Histopathology 2019, 75, 118-127. [CrossRef]

20. Schneider, S.; Thurnher, D.; Kloimstein, P.; Leitner, V.; Petzelbauer, P.; Pammer, J.; Brunner, M.; Erovic, B.M. Expression of the Sonic hedgehog pathway in squamous cell carcinoma of the skin and the mucosa of the head and neck. Head Neck 2011, 33, 244-250. [CrossRef]

21. Gonzalez, A.C.; Ferreira, M.; Ariel, T.; Reis, S.R.A.; Andrade, Z.; Medrado, A.P. Immunohistochemical evaluation of hedgehog signalling in epithelial/mesenchymal interactions in squamous cell carcinoma transformation: A pilot study. J. Oral Pathol. Med. 2015, 45, 173-179. [CrossRef]

22. Yu, J.; Wu, R.; Wang, Z.; Chen, S.; Chen, S.; Guo, G.; Liu, Z. Cyclopamine Suppresses Human Esophageal Carcinoma Cell Growth by Inhibiting Glioma-Associated Oncogene Protein-1, a Marker of Human Esophageal Carcinoma Progression. Med Sci. Monit. 2019, 25, 1518-1525. [CrossRef]

23. Mozet, C.; Stoehr, M.; Dimitrova, K.; Dietz, A.; Wichmann, G. Hedgehog targeting by cyclopamine suppresses head and neck squamous cell carcinoma and enhances chemotherapeutic effects. Anticancer. Res. 2013, 33, 2415-2424. [PubMed]

24. Hehlgans, S.; Booms, P.; Güllülü, Ö.; Sader, R.; Rödel, C.; Balermpas, P.; Rödel, F.; Ghanaati, S. Radiation Sensitization of Basal Cell and Head and Neck Squamous Cell Carcinoma by the Hedgehog Pathway Inhibitor Vismodegib. Int. J. Mol. Sci. 2018, 19, 2485. [CrossRef]

25. Essid, N.; Chambard, J.C.; Elgaaïed, A.B. Induction of epithelial-mesenchymal transition (EMT) and Gli1 expression in head and neck squamous cell carcinoma (HNSCC) spheroid cultures. Bosn. J. Basic Med Sci. 2018, 18, 336-346. [CrossRef] [PubMed]

26. Rodrigues, M.F.S.D.; Miguita, L.; De Andrade, N.P.; Heguedusch, D.; Rodini, C.O.; Moyses, R.A.; Toporcov, T.N.; Gama, R.R.; Tajara, E.E.; Nunes, F.D. GLI3 knockdown decreases stemness, cell proliferation and invasion in oral squamous cell carcinoma. Int. J. Oncol. 2018, 53, 2458-2472. [CrossRef] [PubMed]

27. Luo, J. Glycogen synthase kinase $3 \beta$ (GSK3 $\beta)$ in tumorigenesis and cancer chemotherapy. Cancer Lett. 2009, 273, 194-200. [CrossRef]

28. Trnski, D.; Sabol, M.; Gojevic, A.; Martinić, M.; Ozretic, P.; Musani, V.; Ramić, S.; Levanat, S. GSK3 $\beta$ and Gli3 play a role in activation of Hedgehog-Gli pathway in human colon cancer-Targeting GSK3 $\beta$ downregulates the signaling pathway and reduces cell proliferation. Biochim. Biophys. Acta (BBA) Mol. Basis Dis. 2015, 1852, 2574-2584. [CrossRef]

29. Kinzler, K.W.; Ruppert, J.M.; Bigner, S.H.; Vogelstein, B. The GLI gene is a member of the Kruppel family of zinc finger proteins. Nature 1988, 332, 371-374. [CrossRef]

30. Kinzler, K.W.; Vogelstein, B. The GLI gene encodes a nuclear protein which binds specific sequences in the human genome. Mol. Cell. Boil. 1990, 10, 634-642. [CrossRef]

31. Zhang, X.; Harrington, N.; Moraes, R.C.; Wu, M.-F.; Hilsenbeck, S.G.; Lewis, M.T. Cyclopamine inhibition of human breast cancer cell growth independent of Smoothened (Smo). Breast Cancer Res. Treat. 2008, 115, 505-521. [CrossRef] [PubMed] 
32. Nayak, A.; Siddharth, S.; Das, S.; Nayak, D.; Sethy, C.; Kundu, C.N. Nanoquinacrine caused apoptosis in oral cancer stem cells by disrupting the interaction between GLI1 and $\beta$ catenin through activation of GSK3 $\beta$. Toxicol. Appl. Pharmacol. 2017, 330, 53-64. [CrossRef] [PubMed]

33. Schindelin, J.; Arganda-Carreras, I.; Frise, E.; Kaynig, V.; Longair, M.; Pietzch, T.; Preibisch, S.; Rueden, C.; Saalfeld, S.; Schmid, B.; et al. Fiji: An open source platform for biological-image analysis. Nature Meth. 2012, 9, 679-682. [CrossRef] [PubMed]

(C) 2020 by the authors. Licensee MDPI, Basel, Switzerland. This article is an open access article distributed under the terms and conditions of the Creative Commons Attribution (CC BY) license (http://creativecommons.org/licenses/by/4.0/). 